\title{
Article \\ A Single Base Insertion in F9 Causing Hemophilia B in a Family of Newfoundland-Parti Standard Poodle Hybrid Dogs
}

\author{
Henrike Kuder ${ }^{1,2} \oplus$, Liubov Sandzhieva-Vuzzo ${ }^{3}$, Alexandra Kehl ${ }^{1} \oplus$, Jonathan M. Rappaport ${ }^{3}$, Elisabeth Müller ${ }^{1}$ \\ and Urs Giger $2,4, *(\mathbb{D}$ \\ 1 Laboklin GmbH \& Co. KG (Labogen), Steubenstraße 4, D-97688 Bad Kissingen, Germany; \\ henrike.kuder@uzh.ch (H.K.); kehl@laboklin.com (A.K.); mueller@laboklin.com (E.M.) \\ 2 Vetsuisse Faculty, University of Zürich, Winterthurerstrasse 260, CH-8057 Zürich, Switzerland \\ 3 Advanced Veterinary Care Center, 8920 W. State Road 84, Davie, FL 33324, USA; \\ liubovsandzhieva@gmail.com (L.S.-V.); jrappaport@advetcc.com (J.M.R.) \\ 4 Section of Medical Genetics (PennGen), School of Veterinary Medicine, University of Pennsylvania, \\ 3900 Delancey Street, Philadelphia, PA 19104, USA \\ * Correspondence: giger@upenn.edu
}

check for

updates

Citation: Kuder, H.;

Sandzhieva-Vuzzo, L.; Kehl, A.;

Rappaport, J.M.; Müller, E.; Giger, U.

A Single Base Insertion in F9 Causing

Hemophilia B in a Family of

Newfoundland-Parti Standard

Poodle Hybrid Dogs. Genes 2021, 12,

1491. https://doi.org/10.3390/

genes12101491

Academic Editor: Jeffrey M. Kidd

Received: 1 September 2021

Accepted: 23 September 2021

Published: 24 September 2021

Publisher's Note: MDPI stays neutral with regard to jurisdictional claims in published maps and institutional affiliations.

Copyright: (C) 2021 by the authors. Licensee MDPI, Basel, Switzerland. This article is an open access article distributed under the terms and conditions of the Creative Commons Attribution (CC BY) license (https:/ / creativecommons.org/licenses/by/ $4.0 /)$.

\begin{abstract}
Hemophilia B is an x-linked recessive hereditary coagulopathy that has been reported in various species. We describe a male Newfoundland-Parti Standard Poodle hybrid puppy and its family with hemophilia B from clinical manifestations to the molecular genetic defect. The index case presented for dyspnea was found to have a mediastinal hematoma, while surgical removal and transfusion support brought some relief, progressive hematoma formations led to humane euthanasia. Sequencing the $F 9$ exons revealed a single nucleotide insertion resulting in a frameshift in the last exon (NM_001003323.2:c.821_822insA), predicted to result in a premature stop codon (NP_001003323.1:p.Asn274LysfsTer23) with a loss of 178 of 459 amino acids. The unexpected high residual plasma factor IX activity ( $3 \%$ to $11 \%$ of control) was likely erroneous, but no further studies were performed. Both the purebred Newfoundland dam and her sister were heterozygous for the insertion. Five additional male offspring developed severe hemorrhage and were hemizygous for the F9 variant and/or had a prolonged aPTT. In contrast, other male littermates had normal aPTTs and no evidence of bleeding. While they are related to a common Newfoundland granddam, the prevalence of the pathogenic variant in the Newfoundland breed is currently unknown. These clinical to molecular genetic studies illustrate that precision medicine is achievable in clinical companion animal practice.
\end{abstract}

Keywords: bleeding disorder; coagulopathy; factor IX; frameshift mutation; canine; intrinsic pathway; X-linked recessive; partial thromboplastin time

\section{Introduction}

Hemophilia A and B are X-linked recessively inherited coagulopathies that may cause severe bleeding in humans and domestic animals. The conditions are caused by mutations in the F8 or F9 gene, leading to reduced plasma activity of coagulation factor (F) VIII or IX, respectively [1-6]. Several F8 and F9 gene variants have been reported in bleeding dogs of various breeds [7-13] and are listed in the Online Mendelian Inheritance of Animals database (OMIA [14], Hemophilia A 000437-9615, and Hemophilia B 000438-9615).

This clinical and molecular genetic study describes a male Newfoundland-Parti Standard Poodle hybrid (NewfyPoo) puppy with hemophilia B and severe clinical bleeding due to a novel F9 frameshift variant, and the genotypic and phenotypic assessment of its family members. 


\section{Materials and Methods}

\subsection{Dogs and Samples}

The index case, a privately owned NewfyPoo, is designated Case \#1. He and his relatives were assessed clinically and diagnostically. Coagulation factor analyses were performed in fresh frozen citrated plasma at Comparative Coagulation Laboratory, Cornell University, Ithaca, NY, USA while molecular genetic studies were done at Labogen (Laboklin $\mathrm{GmbH}$ \& Co. KG, Bad Kissingen, Germany). To determine the molecular genetic defect in the index case, ethylenediamine tetraacetic acid (EDTA)-anticoagulated blood samples left-over from routine hematology testing were used. Genotyping by buccal swabs was then offered to the breeder and owners of related dogs for informed medical management and breeding plans. In addition, archived DNA samples from Newfoundland dogs (including Landseers) and Standard Poodles sent for routine diagnostic testing at Labogen were examined for the presence of the novel F9 variant. The use of left-over samples at Labogen was approved by the governmental animal care and use committee in Bavaria, Germany.

\subsection{Molecular Genetic Analysis}

Genomic DNA was isolated from blood and buccal swab samples with GenElute ${ }^{\mathrm{TM}}$ Blood Genomic DNA Kit (Sigma Aldrich/ Merck, Darmstadt, Germany) and the MagNA Pure 96 system using DNA Tissue Lysis Buffer and viral NA Small kit (Roche, Basel, Switzerland), according to manufacturers' instructions. Based upon the published reference canine F9 genome DNA sequence (CanFam3.1, NC_006621.3 [15]), primers were designed in adjacent intronic sequences to amplify all eight canine $F 9$ exons including exon-intron boundaries and splice sites (Supplemental Table S1). Primers were synthesized by Eurofins Genomics GmbH (Ebersberg, Germany). DNA fragments were amplified by polymerase chain reaction (PCR) utilizing established protocols with a premixed FastStart Mastermix (Roche), and an automated thermal cycler (Bioer Technology Co., Ltd., Hangzhou, China).

Sanger sequencing was performed with an ABI Genetic Analyzer 3130 (Applied Bioscience, Thermo Fisher Scientific, Waltham, MA, USA), and the amplified products were analyzed with a BigDye ${ }^{\mathrm{TM}}$ Terminator v1.1 Cycle Sequencing Kit (Thermo Fisher Scientific). Electropherograms were assessed by SeqScanner (Applied Biosystems) [16], and DNA sequences were aligned to published cDNA sequences for canine F9 (NC_006621.3 (CanFam3.1), NC_049780.1 (UNSW_CanFamBas_1.0), NC_049299.1(UMICH_Zoey_3.1), NC_049260.1 (UU_Cfam_GSD_1.0), NC_006621.4 (Dog10K_Boxer_Tasha), NC_051843.1 (ROS_Cfam1.0) [15] using an open-source multi-alignment tool from the National Center for Biotechnology Information (Nucleotide Blast) [17]. The F9 DNA sequences of Case \#1 were compared to an unrelated healthy Newfoundland dog sequenced from an archived DNA sample. The Dog Biomedical Variant Database Consortium (DBVDC), which contains genomes from 582 dogs representing 126 breeds, including two Newfoundland dogs, one Landseer, and two Standard Poodles, was screened by BCF-tools view for the VCF file DBVDC [18]. To determine the prevalence of the putative pathogenic variant in the Newfoundland and Poodle breeds, DNA samples from additional 75 Newfoundland dogs and 75 Poodles were genotyped. A web-based DNA translation tool from ExPASy (SIB Bioinformatics Resource Portal) [19] was applied to predict the FIX amino acid sequence.

\subsection{Genotyping}

For genotype screening of DNA samples, a variant-specific TaqMan ${ }^{\circledR}$ SNP Genotyping Assay (Thermo Fisher Scientific) was designed utilizing the published genomic DNA reference sequence of canine F9 (CanFam3.1, NC_006621.3 [15]), (Supplemental Table S1). To detect the mutant allele sequence, the probe was labeled with FAM ${ }^{\mathrm{TM}}$ dye, the wildtype allele probe was labeled with $\mathrm{VIC}^{\mathrm{TM}}$ dye (Thermo Fisher Scientific). A Rotor-Gene 6000 (Corbett) was used for amplification by standard real-time PCR protocol as well as allelic discrimination. 


\subsection{Family Study}

The breeder of Case \#1 was contacted and clinical, laboratory test results, and breeding information related to the kennel were obtained to determine the potential extent of the disease in the family and prepare a pedigree for the index case. Based on the diagnosis of hemophilia B in the index case, the dam (purebred Newfoundland dog) and sire (purebred Standard Parti Poodle) were tested by the breeder for published F9 variants by Wisdom Panel (Portland, OR, USA) [20] and Vetnostics Laboratories (Hamilton Township, NJ, USA) [21] prior to our involvement. After being contacted by us, the breeder then tested all related male offspring with an activated partial thromboplastin time (aPTT) at their primary care clinics. Once the pathogenic $F 9$ variant was discovered in Case \#1, genotyping with buccal swabs from the dogs related to the index case was offered to the breeder free of charge. Breeders and owners of additional maternal ancestors for the index case were contacted to examine the genotypes of their dogs, but these animals were either deceased or not made available.

\section{Results}

\subsection{Case Report}

A three-month-old male intact NewfyPoo dog (index case, Case \#1) was presented with lethargy, poor appetite, and unlocalizable pain to the Advanced Veterinary Care Center in Davie, FL, USA (Day 1). Other than mild bleeding from the mouth after losing a deciduous tooth the day prior to presentation, no evidence of abnormal bleeding was previously observed in this individual or any littermates. Values of a routine complete blood cell count, serum chemistry screen, and prothrombin time (PT) of Case \#1 were within the reference ranges for puppies, but the activated partial thromboplastin time (aPTT) was markedly prolonged (240 s; reference range, 72-102 s; Table 1).

Table 1. Routine hemostasis test results for a bleeding male Newfoundland-Parti Standard Poodle puppy with hemophilia B: Case \#1.

\begin{tabular}{|c|c|c|c|c|}
\hline Day & Time of Day & $\begin{array}{l}\text { PCV (\%)/ } \\
\text { TP (g/dL) }\end{array}$ & $\begin{array}{c}\mathrm{aPTT} / \\
\mathrm{PT}(\mathrm{s}) *\end{array}$ & Comments \\
\hline 1 & 17 & $30 / \mathrm{ND}$ & $240 / 11$ & Admission, dyspneic \\
\hline \multirow{4}{*}{2} & 08 & $13 / 5.0$ & $>300 / 11$ & Progressive dyspnea, ventilated \\
\hline & 10 & ND/ND & $162 / N D$ & Post pRBC transfusions ** \\
\hline & 14 & $18 / 5.0$ & 133/ND & $\begin{array}{l}\text { Post thoracic surgery and } \\
\text { FFP transfusion }\end{array}$ \\
\hline & 23 & $\mathrm{ND} / \mathrm{ND}$ & $135 / \mathrm{ND}$ & Post additional FFP transfusion \\
\hline 3 & 07 & $20 / 6.0$ & ND/ND & Clinically stable \\
\hline 4 & 14 & $24 / 5.0$ & $126 / 11$ & Clinically stable \\
\hline \multirow{2}{*}{5} & 10 & $35 / 7.0$ & $124 / \mathrm{ND}$ & Prior to FFP transfusion ** \\
\hline & 22 & $34 / 8.0$ & $129 / \mathrm{ND}$ & Post FFP transfusion \\
\hline 6 & 10 & $\mathrm{ND} / \mathrm{ND}$ & $105 / \mathrm{ND}$ & Post FFP transfusion \\
\hline 10 & 08 & $41 / 8.0$ & $>300 / \mathrm{ND}$ & Severe chest wall hematoma \\
\hline 11 & 10 & $20 / 6.0$ & ND/ND & Euthanasia \\
\hline
\end{tabular}

Reference Ranges $\quad 30-45 / 5.5-7.2 \quad 72-102 / 11-17$

* Coag Dx ${ }^{\mathrm{TM}}$ Analyzer (IDEXX, Portland, ME, USA) with citrated fresh whole blood. ${ }^{* *}$ prior to and post refer to time measured related to nearby transfusion. Dog was discharged from clinic between Day 7 to Day 9. PCV, packed cell volume; TP, total protein; aPTT, activated partial thromboplastin time; PT, prothrombin time; ND, not determined; pRBC, packed red blood cells; FFP, fresh frozen plasma. Abnormal values are shown bold.

Thoracic radiographs showed a soft tissue mass in the mediastinum causing ventral displacement of the esophagus and trachea (Figure 1a,b). The puppy was hospitalized for diagnostic evaluation and supportive care, which included blood type and crossmatched transfusions. The next morning (Day 2), the puppy had to be intubated due to labored breathing. In addition to the mediastinal mass, pleural effusion was detected by ultrasound. Based on the isolated prolongation of the aPTT, a hereditary coagulopathy was suspected, 
and citrated plasma for coagulation factor analyses was sent to Comparative Coagulation Laboratory, Cornell University, Ithaca, NY, USA. The results received on Day 7 revealed a low plasma FIX activity consistent with hemophilia B (Table 2).

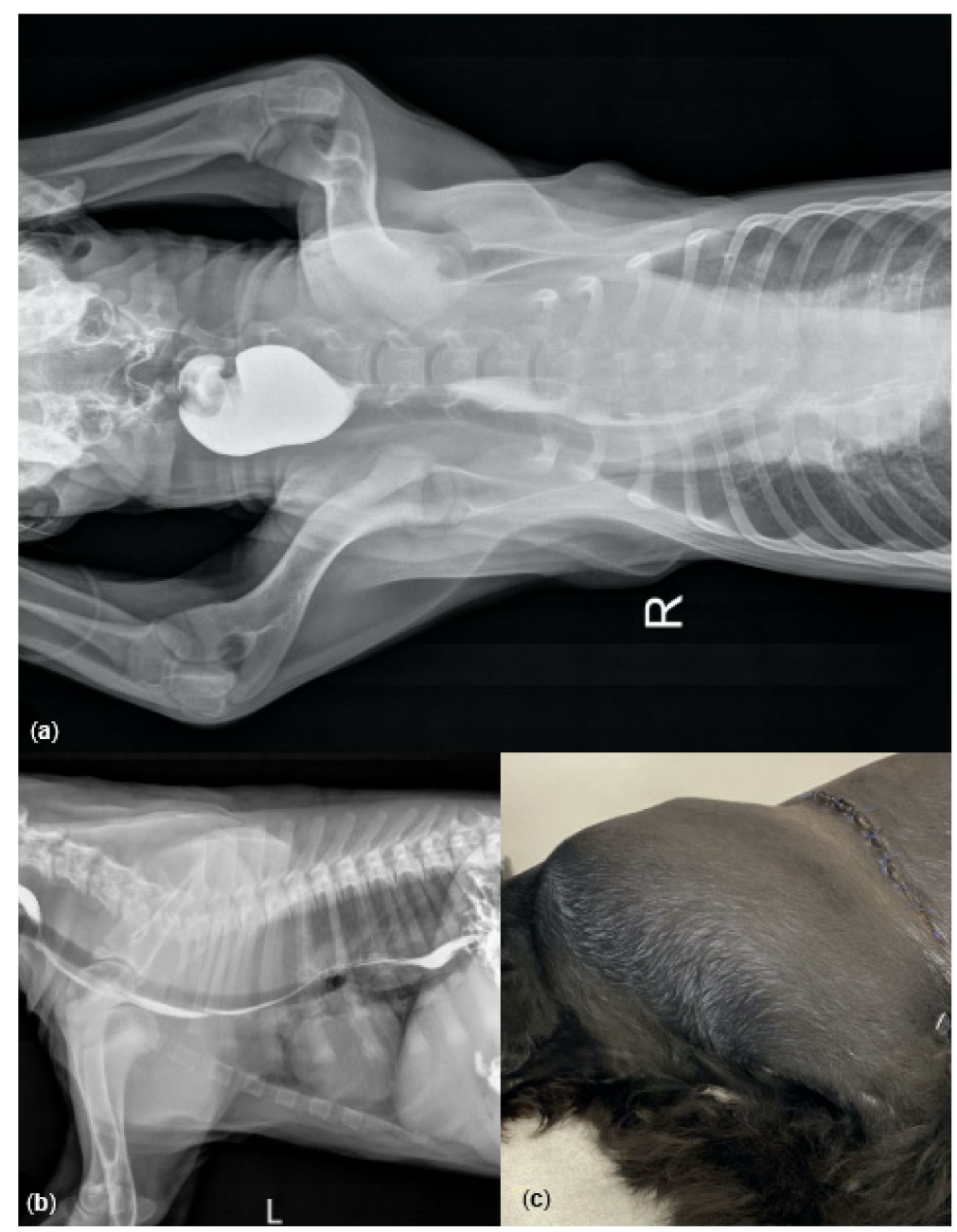

Figure 1. Clinical features showing chest radiographs and hematomas in a Newfoundland-Parti Standard Poodle hybrid puppy with hemophilia B: Case \#1. Radiographic views of ventrodorsal (a) and lateral (b) thorax after a bolus of barium suspension showing tracheal and esophageal displacement at the time of admission (Day 1). Photograph of left chest wall post-surgery on Day 10 showing a large subcutaneous hematoma (c).

Extubation was attempted on Day 3, but the puppy became very dyspneic. Thoracocentesis did not improve dyspnea, and a thoracotomy to drain the chest and stop bleeding was performed under general anesthesia with assisted ventilation. Purpura covering the entire mediastinum was observed, but there was no active bleeding. The large mediastinal mass causing airway compression was removed. Based on gross appearance and histology, the mass was identified as a hematoma.

Fresh frozen plasma (FFP; $20 \mathrm{~mL} / \mathrm{kg}$ ), packed red blood cells (pRBCs; $16 \mathrm{~mL} / \mathrm{kg}$ ), crystalloid, and canine albumin were administered intravenously on Day 4. After FFP administration, the aPTT was only slightly prolonged (126 s; Table 1). The puppy appeared to respond well to post-surgical care and was discharged on Day 7.

On Day 10 (eight days after surgery), the puppy was presented for lethargy, a $10 \times 20 \mathrm{~cm}$ subcutaneous hematoma over the left shoulder (Figure 1c), and right forelimb lameness. During the examination no signs of dyspnea were observed, and the thoracotomy skin incision seemed to be healing well (Figure 1c). The aPTT was again severely prolonged, and 
a citrated plasma sample was submitted for confirmatory coagulation factor analyses which revealed a plasma FIX activity of 3\% (previously $11 \%$ ), without evidence of neutralizing anti-FIX antibodies (also called inhibitors; Table 3). Diagnosis of hemophilia B, severe recurring hemorrhage, and an expected poor prognosis in large breed dogs [3] led the owner to elect humane euthanasia. A necropsy was not performed.

Table 2. Plasma hemostasis panel test results for a bleeding male Newfoundland-Parti Standard Poodle hybrid puppy with hemophilia B: Case \#1.

\begin{tabular}{ccccc}
\hline Hemostatic & Unit & \multicolumn{2}{c}{ Results } & \multirow{2}{*}{ Reference Range } \\
Parameters & & Day 2 & Day 10 & \\
\hline PT & $\mathrm{s}$ & 11.9 & ND & $11.0-15.5$ \\
aPTT & $\mathrm{s}$ & 25.0 & ND & $8.5-15.5$ \\
TCT & $\mathrm{s}$ & 4.5 & ND & $5.0-9.0$ \\
FVII & $\%$ & 123 & 100 & $50-150$ \\
FVIII & $\%$ & 104 & 51 & $50-200$ \\
FIX & $\%$ & 11 & 3 & $50-150$ \\
FX & $\%$ & 166 & 106 & $80-175$ \\
FXI & $\%$ & 56 & $60-150$ \\
FXII & $\%$ & 84 & 64 & $60-150$ \\
vWF & $\%$ & 141 & ND & $70-180$ \\
FIX Inhibitor & BU $/ \mathrm{mL}$ & ND & 0.15 & $0-1.00$ \\
\hline
\end{tabular}

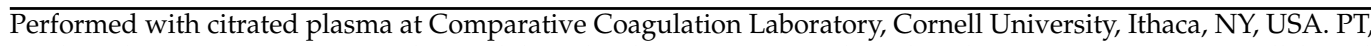
prothrombin time; aPTT, activated partial thromboplastin time; TCT, thrombin clotting time; vWF, von Willebrand factor; \%, activity of factor in percent of pooled plasma from healthy dogs; BU $/ \mathrm{mL}$, Bethesda unit per $\mathrm{mL}$ (a BU titer of $<0.5$ is considered not inhibiting activity of endogenous or transfused coagulation factors); ND, not determined. Abnormal values are shown bold.

Table 3. Characteristics of hemophilia B in dogs with known F9 variants associated with hemophilia B in dogs.

\begin{tabular}{|c|c|c|c|c|c|c|c|}
\hline Breed $^{a}$ & Position in Genome & $\begin{array}{l}\text { cDNA \& Amino } \\
\text { Acid Position }\end{array}$ & $\begin{array}{c}\text { Type of } \\
\text { Mutation }\end{array}$ & $\begin{array}{l}\text { FIX Activity } \\
\text { (\%) }^{\text {b }}\end{array}$ & $\operatorname{aPTT}(s)^{c}$ & Clinical Signs & Occurrence \\
\hline $\begin{array}{c}\text { Cairn Terrier } \\
{[7,22]}\end{array}$ & $\begin{array}{l}\text { g.109532018G }>\mathrm{A} \\
\text { Exon } 8\end{array}$ & $\begin{array}{l}\text { c. } 1253 \mathrm{G}>\mathrm{A} \\
\text { p.Gly418Glu * }\end{array}$ & missense & 0 & $70-90$ & $\begin{array}{c}\text { Hemarthrosis, } \\
\text { hematoma, CNS } \\
\text { bleeding, mediastinal \& } \\
\text { cavity bleeding }\end{array}$ & Research Colony \\
\hline Lhasa Apso [8] & $\begin{array}{c}\text { g.109521356_109521361 } \\
\text { delinsT } \\
\text { Intron 5 }\end{array}$ & $\begin{array}{l}\text { c.548_553delinsT } \\
\text { p.Arg183LeufsTer3 }\end{array}$ & $\begin{array}{l}\text { deletion, } \\
\text { insertion }\end{array}$ & $<1$ & $48 / 60$ & $\begin{array}{l}\text { Hemorrhage, } \\
\text { not specified }\end{array}$ & Single cases \\
\hline $\begin{array}{c}\text { Labrador } \\
\text { Retriever [9] }\end{array}$ & $\begin{array}{l}\text { complete deletion of } \\
\text { factor IX gene }\end{array}$ & - & deletion & 1 & $>60$ & $\begin{array}{c}\text { Hematoma, } \\
\text { hemarthrosis, prolonged } \\
\text { bleeding from minor } \\
\text { wounds }\end{array}$ & Family \\
\hline $\begin{array}{l}\text { Pit Bull Terrier } \\
{[10]}\end{array}$ & $\begin{array}{l}\text { deletion of entire } \\
5 \text { 'region extending to } \\
\text { exon } 6\end{array}$ & - & deletion & $<1$ & $86-120$ & $\begin{array}{c}\text { Hemarthrosis, } \\
\text { intramuscular } \\
\text { hematoma, epistaxis }\end{array}$ & Single case \\
\hline $\begin{array}{c}\text { Airedale Terrier } \\
{[10]}\end{array}$ & $\begin{array}{c}\text { g.109532012_13ins } \\
(5 \mathrm{~kb}) \\
\text { Exon } 8\end{array}$ & $\begin{array}{l}\text { c. } 1247 \_1248 \text { ins } \\
(5 \mathrm{~kb})\end{array}$ & insertion & $<1$ & $86-120$ & $\begin{array}{c}\text { Hemarthrosis, } \\
\text { intramuscular } \\
\text { hematoma, epistaxis }\end{array}$ & Single case \\
\hline $\begin{array}{l}\text { German } \\
\text { Wirehaired } \\
\text { Pointer [11] }\end{array}$ & $\begin{array}{c}\text { g.109521130_10952113 } \\
\text { 1insLINE1 } \\
\text { Intron 5 }\end{array}$ & - & insertion & $2.4-6.4$ & Prolonged $^{\mathrm{d}}$ & $\begin{array}{c}\text { Hematoma, } \\
\text { hemarthrosis, excessive } \\
\text { bleeding after surgery \& } \\
\text { minor wounds } \\
\text { Spontaneous }\end{array}$ & $\begin{array}{l}\text { several cases } \\
\text { in Northern } \\
\text { America \& } \\
\text { Europe }\end{array}$ \\
\hline $\begin{array}{l}\text { Rhodesian } \\
\text { Ridgeback [12] }\end{array}$ & $\begin{array}{l}\text { g.109530847G }>A \\
\text { Exon } 7\end{array}$ & $\begin{array}{l}\text { c.731G>A } \\
\text { p.Gly237Glu }\end{array}$ & missense & $\sim 1$ & Prolonged $^{\mathrm{d}}$ & $\begin{array}{l}\text { hemorrhage \& severe } \\
\text { bleeding after minor } \\
\text { surgeries }\end{array}$ & Family \\
\hline Hovawart [13] & $\begin{array}{l}\text { g.109501492delC } \\
\text { Promoter }\end{array}$ & - & missense & $2-5$ & $\begin{array}{l}3-5 \text { fold } \\
\text { increase }\end{array}$ & $\begin{array}{c}\text { Umbilical \& gingival } \\
\text { bleeding, hemarthrosis, } \\
\text { hematomas \& } \\
\text { hemorrhage after surgery } \\
\text { \& vaccination }\end{array}$ & Family \\
\hline $\begin{array}{l}\text { Newfoundland } \\
\text { \& Standard } \\
\text { Poodle hybrid } \\
\text { dogs * }\end{array}$ & $\begin{array}{c}\text { g.109531586_109531587 } \\
\text { insA } \\
\text { Exon } 8\end{array}$ & $\begin{array}{l}\text { c.821_822insA } \\
\text { p.Asn274LysfsTer23 }\end{array}$ & insertion & $11 / 3$ & $25^{\mathrm{e}}$ & $\begin{array}{c}\text { Hemarthrosis, } \\
\text { hematoma, hemorrhage } \\
\text { when losing deciduous } \\
\text { teeth \& after vaccination }\end{array}$ & Family \\
\hline
\end{tabular}

${ }^{\text {a }}$ Listed in order of year published; ${ }^{\mathrm{c}}$ Normal upper limit of aPTT is $\sim 25.0 \mathrm{~s} ;{ }^{\mathrm{d}}$ No specific times given; ${ }^{\mathrm{e}}$ Normal upper limit of aPTT is $15.5 \mathrm{~s}$, several other aPTT measurements with inhouse instruments were also markedly prolonged (Table 1). ${ }^{\mathrm{b}}$ FIX activity, compared to pooled canine sample plasma assigned $100 \%$; aPTT, normal ranges varied between $8-30 \mathrm{~s}$; Updated variant nomenclature according to Human Genome Variation Society (HGVS) Recommendations for the Description of Sequence Variants [23]. Reference canine F9 gene sequence (CanFam3.1, NC_006621.3, ChrX:109,501,341 to 109,533,798), reference canine F9 amino acid sequence (NP_001003323.1) and reference canine F9 cDNA sequence (NM_001003323.2) [15]. * Indicates family of dogs studied in this report. Canine hemophilia B cases without molecular genetic studies are not included. 


\subsection{Molecular Genetic Analysis}

Exonic and adjacent intronic F9 gene sequence for Case \#1, the published canine reference genome sequence (CanFam3.1, NC_006621.3), recent canine reference genome sequences (NC_051843.1, NC_049260.1, NC_006621.4) [15] and the genomic sequence of a healthy unrelated Newfoundland dog were identical except for a single non-synonymous variant: a single adenine base insertion in exon 8 of the F9 gene, ChrX:g.109,531,586_109,531, 587insA (CanFam3.1, NC_006621.3) [15] in Case \#1. The NM_001003323.2:c.821_822insA single base insertion results in a frameshift that changes the wild type amino acid sequence starting at position NP_001003323.1:p.Asn274Lys [15]. After 23 amino acids, there is a predicted premature stop codon (NP_001003323.1:p.Asn274LysfsTer23) (Figures 2 and 3) Ref.[15,19,23]. This stop codon at position 297 is followed by additional premature stop codons at NP_001003323.1:p.Asn301* and NP_001003323.1:p.Lys302*.

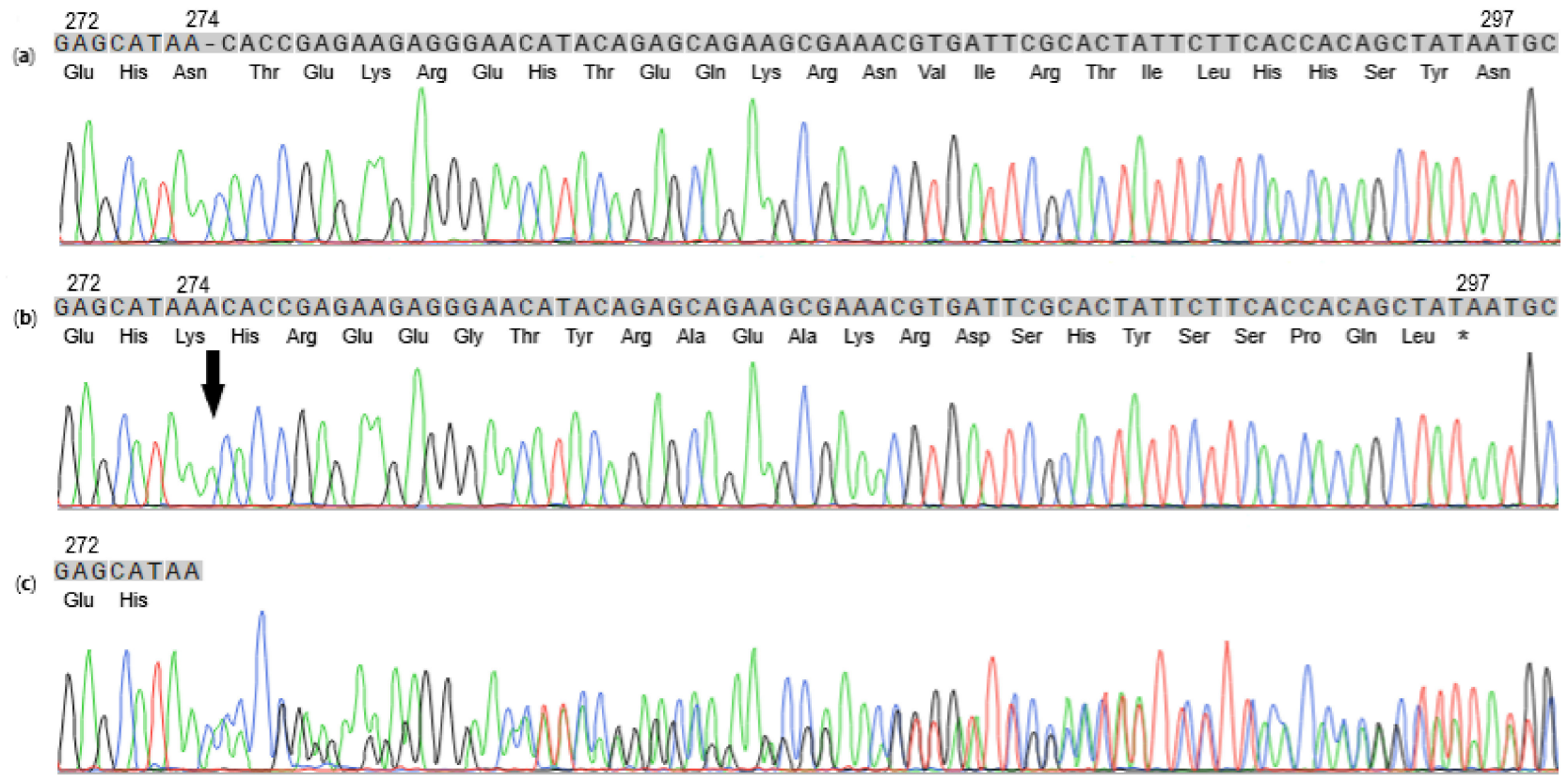

Figure 2. Sanger sequence data for the region of $F 9$ surrounding the single base insertion variant for a wild-type Newfoundland $\operatorname{dog}(\mathbf{a})$, a Newfoundland-Parti Standard Poodle with hemophilia B (Case \#1) (b), and the dam for Case \#1 (c). The F9 sequence for the $5^{\prime}$ region of exon 8 and the corresponding amino acid sequence are shown. Sequence for the hemizygous index case with the single adenine base insertion NM_001003323.2:c.821_822insA (arrow) results in a reading frameshift. The first predicted premature stop codon NP_001003323.1:p.Asn274LysfsTer23 is marked by an asterisk. Sequence for the dam of the index case shows heterozygosity for the insertion. The top lines show the DNA codons in grey boxes, with the predicted amino acid sequences below, starting with amino acid 272 in the canine amino acid sequence (NP_001003323.1), which is concordant to amino acid 281 in the human amino acid sequence (NP_000124.1) of F9.

\subsection{Family and Breed Studies}

Using $F 9$ primer pair 8 (Supplemental Table S1) for exon 8, DNA samples from ten related and one unrelated Newfoundland dog were sequenced. The unrelated Newfoundland dog's DNA had no sequence variations compared to published wild-type sequences. Moreover, screening by TaqMan ${ }^{\circledR}$ SNP Genotyping Assay of archived samples from 75 Newfoundland dogs and 75 Poodles did not reveal other carriers or affected animals (all homozygous wild-type).

Within the family, the dam (\#2) of the index case (\#1) and her sister (\#5) were both heterozygous for the $F 9$ exon 8 insertion, and three of their male puppies (\#3,\#6,\#7) were hemizygous for the insertion. Male \#8, female \#4 (a littermate of the index case), and two female offspring $(\# 9, \# 10)$ of $\# 5$ and a Parti-Standard Poodle were homozygous wild-type (Figure 3). 


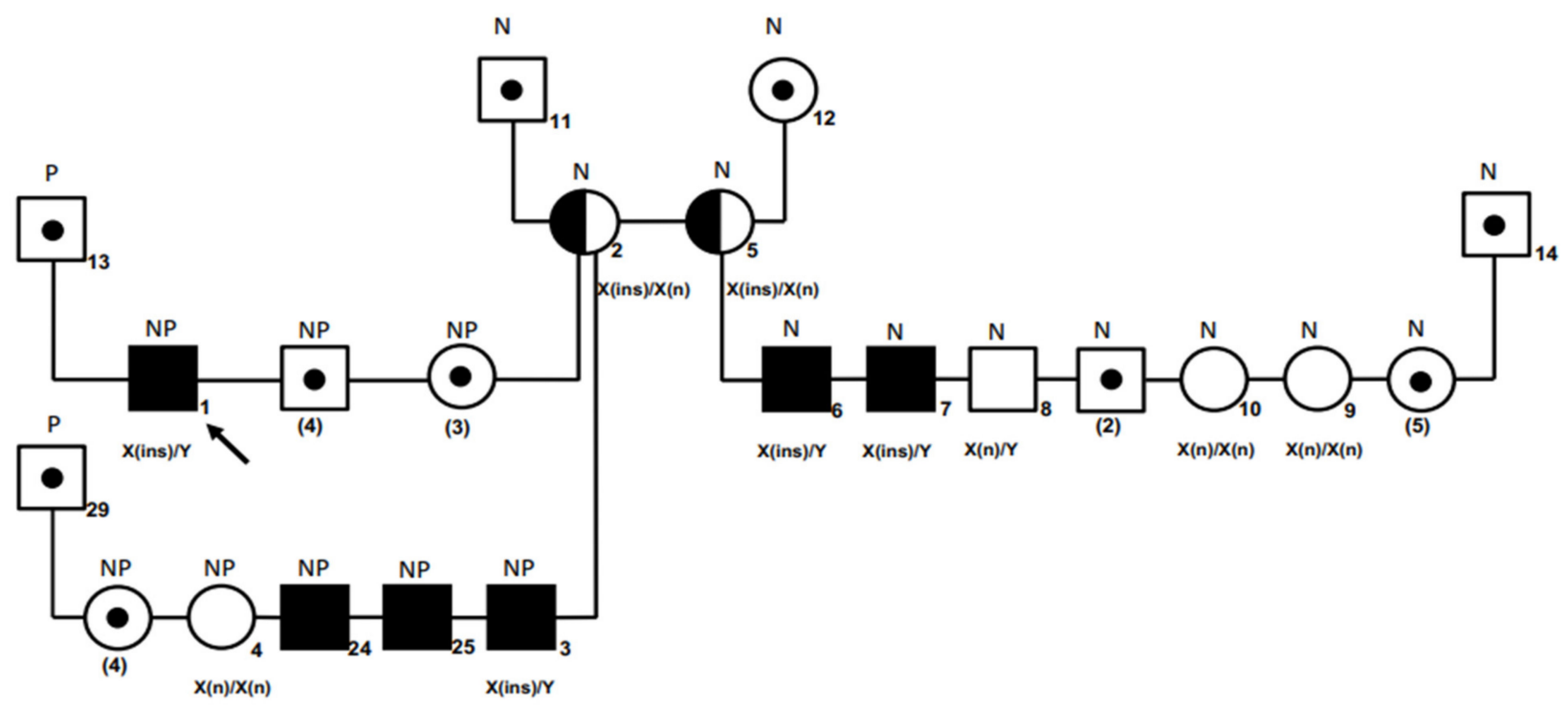

Figure 3. Pedigree of a hemophiliac Newfoundland-Parti Standard Poodle family, with results of genotyping and aPTT results. Squares and circles represent males and females, respectively. Filled symbols indicate clinically bleeding male dogs hemizygous for the $F 9$ variant and/or having a prolonged aPTT. All affected animals displayed abnormal bleeding. Half-filled symbols indicate females who are carrier of the F9 variant. The black arrow refers to the index case (Case \#1). Symbols with a dot but with numbers in brackets indicate number of dogs that were not available for genotyping. The six male offspring in this category had normal aPTTs (squares with dot). Genotyping results are shown below each square or circle (X and Y represent the X- and Y-chromosomes; (n), wild-type; (ins), insertion (NM_001003323.2:c.821_822insA [15]). Abbreviations: N, purebred Newfoundland dog; NP, Newfoundland-Parti Standard Poodle: P, Standard Poodle.

The breeder had all male offspring of the three litters tested by aPTT. Three NewfyPoo hybrids and two Newfoundland dogs were found to have a prolonged aPTT (\#3, \#6, \#7, $\# 24, \# 25)$, while six other males had normal aPTT values. Three males with a prolonged aPTT were hemizygous for the F9 variant (\#3,\#6, \#7; Figure 3). Shortly thereafter, they developed intermittent lameness with joint swelling (hemarthrosis). One of them also developed severe internal hemorrhage and was euthanized. Another bled after vaccination at eight weeks of age and was euthanized. Initially, unaware of the bleeding disorder, the breeder had sold all puppies to be neutered and not to be bred. The breeder of the common granddam of the hemizygous males was contacted and was unaware of a bleeding disorder in any of the dogs or their offspring until notified of the index case by the breeder and authors. The granddam was not available for testing (Figure 3). The great-granddam was not bred after the litter producing the granddam of the index case and had since passed away.

\section{Discussion}

This is the first report of hemophilia B in Newfoundland dogs which has also affected Newfoundland-Standard Poodle hybrids. The pathogenic mutation is a single base insertion in exon 8 of $F 9$ (NM_001003323.2:c.821_822insA) on the X-chromosome that causes a frameshift encoding a premature stop codon after 23 amino acids (NP_001003323.1:p.Asn274 LysfsTer23) $[15,19,23]$. The variant is in the last exon of $F 9$, which encodes the major portion of the FIX catalytic domain [24]. The insertion results in the loss of 178 of 459 amino acids, including the protease active site serine residue. While a circulating non-functional truncated form of FIX may be present in the plasma of affected animals, no samples were available, and no further protein and expression studies were performed. An early stop codon leads typically to premature mRNA decay when it is located at least 50 nucleotides upstream of the exon-exon junction. As the identified $F 9$ variant in the Newfoundland dogs is located in the last exon, premature mRNA decay appears unlikely [25]. 
The amino acid asparagine at position 274 in canine FIX protein, corresponding to residue 283 in human FIX, is highly conserved among mammalian species (Supplemental Figure S1 [26]). While no nonsense variants at this position have been reported in any human patient with hemophilia B, a missense variant (p.Asn283Asp) at this location was described in one human patient [27]. The European Association for Haemophilia and Allied Disorders (EAHAD) Coagulation Factor IX Gene (F9) Variant Database [28,29] (accessed September 20,2021) currently lists 1244 variants in $F 9$ including insertions and deletions. Slightly more than half (56.9\%) are located in the catalytic domain (exons 7 and 8 ), and the rest involve the remainder of the protein from signal-/pro-peptide to the activation peptide. Of the 206 frameshift variants listed in the human database, 66 insertions or deletions causing frameshifts reside in exon 8 [28,29].

Only a few naturally occurring $F 9$ variants have been reported in animal species (Online Mendelian Inheritance in Animals [OMIA] [14], accessed August 21, 2021), and most of these have been reported in the domestic dog (Table 3). A missense $F 9$ variant in a research colony descendent from an affected Cairn Terrier reported in 1989 represents the very first discovered pathogenic gene variant in the dog [7]. Thereafter, complete and large $F 9$ gene deletions, insertions, nonsense, and missense variants were found in different canine breeds [7-13]. In contrast to a single base insertion as in hemophiliac Newfoundland dogs in this report, truncations of the FIX protein due to a large $5 \mathrm{~kb}$ insertion or five nucleotide deletion in the terminal exon 8 of $F 9$ were found in the Airedale Terrier [10] and Lhasa Apso [8], respectively (Table 3).

Consistent with the predicted complete loss of FIX function, the aPTTs of the index case and related affected Newfoundland and hybrid dogs were severely prolonged, and all affected dogs had a severe bleeding tendency. However, the plasma FIX activities of the index case were not as expected $<1 \%$, but $11 \%$ to $3 \%$ on two separate measurements. The first plasma sample was collected prior to blood transfusion, while the second sample was at least four days after the last plasma transfusion. The half-life of human FIX is 18- $24 \mathrm{~h}$ [1], suggesting that the second plasma FIX activity value of 3\% from the index case may reflect the prior transfusion. Plasma factor activities of the intrinsic coagulation cascade are assessed with aPTT assays and are reported as percentages of the activity in normal human plasma, which by definition has a species-specific $100 \%$ activity of plasma pooled from several healthy dogs $(100 \%$ control). It is possible that there was activation of FVII or other factors in the common pathway leading to fibrin formation and an erroneous FIX activity value of $11 \%$.

A phenotype to genotype comparison of the few other published canine cases of hemophilia B shows a good correlation. Plasma aPTT and FIX activities were markedly reduced to $<5 \%$, and for those expected to be cross-reacting material negative (CRM-), the plasma FIX activity was $<1 \%$ (Table 3 ). In a few cases, additional mRNA, immunoblot, and protein expression studies confirmed these findings: an insertion comprising $5 \mathrm{~kb}$ in exon 8 of $F 9$ has been reported in Airedale Terrier causing alternate splicing and abolishing of the FIX activity $(<1 \%)$ [10]. Similarly, a complete absence of FIX activity due to a single missense mutation in exon 8 was found in the Cairn Terrier research colony [7]. Because no further protein investigations, such as mRNA, immunoblotting and protein expression studies, were pursued here, the reported residual plasma FIX activity of the index case and the presence of a truncated protein remains unknown.

Spontaneous hemarthrosis, hematoma formation without known inciting causes, and increased bleeding after trauma and surgery are well-recognized complications of severe hemophilia in humans, dogs, and other mammalian species, leading to major morbidity and mortality $[1,3,4]$. Similarly, all affected male purebred Newfoundland and hybrid dogs in the family reported here exhibited severe hemorrhage, including mediastinal and subcutaneous hematomas, hemarthrosis, and gingival bleeding following loss of deciduous teeth. In contrast, heterozygous females remained asymptomatic.

Current standard therapy of bleeding dogs with hemophilia B and those needing to undergo surgery includes DEA 1 matched and crossmatched plasma transfusions, 
as successfully performed in the index case. After transfusions, the index case clinically improved and had shortening of the aPTT. Fresh whole blood may be administered when a hemophilic animal is also anemic or in situations where no plasma products are available. Fresh frozen plasma may be used for dogs with either hemophilia A or B, but due to the different sizes of FVIII and FIX proteins, cryo-poor plasma should be administered to dogs with hemophilia B, while cryoprecipitate should be used for hemophilia A. Canine cryo-poor plasma, which is rich in smaller proteins such as FIX, is considerably less expensive than fresh frozen plasma and is preferred for hemophilia B patients, when available $[3,30,31]$.

Hemophiliac patients arise sporadically from de novo mutations in maternal oocytes. Occasionally a variant is passed on over generations via the maternal genomic DNA, for example, the male descendants of Queen Victoria with hemophilia B in the royal families [32]. Similarly, the occurrence of the same $1.5 \mathrm{~kb}$ insertion $F 9$ variant was reported in few families of German Wirehaired Pointers from the USA and Europe [11]. To a lesser extent, familial occurrences of hemophilia B have been described in several Rhodesian Ridgebacks in Germany [12].

The single base insertion segregated completely in the described family of Newfoundland and Newfoundland-Standard Poodle hybrid dogs, with all tested males being hemizygous for the variant showing serious bleeding tendencies. Pedigree analysis and genotyping revealed that the pathogenic variant must have originated in the granddam with two female offspring (heterozygous for variant and thus, carriers) producing affected males or her maternal ancestors, which were purebred Newfoundland dogs; they either passed away or were not available for testing. Thereby, the pathogenic variant in the index case and related dogs was not de novo but passed on maternally to the offspring in this family.

Additionally, the variant described here was not found among 582 canine whole genome sequences deposited in DBVDC [18], including two Newfoundland dogs, one Landseer dog and two Standard Poodles. Moreover, genotyping of 75 Newfoundland dogs and Poodles for the insertion did not find any dogs with the insertion. According to the Comparative Coagulation Laboratory at Cornell University in Ithaca, a national referral center for diagnostics of bleeding disorders in animals, no hemophiliac Newfoundland dogs have been previously found (M.B. Brooks, personal communication, 2021). Thus, these results suggest that the $F 9$ insertion in Newfoundland dogs occurred recently and is restricted to a small family rather than widespread within the breed.

While heterozygous females are clinically asymptomatic, a pathogenic $F 9$ variant may be inferred from pedigree analyses and plasma FIX activity may be half-normal, the best approach is genotyping for the specific pathogenic $F 9$ variant. In this study, the Newfoundland dam of the bleeding index case, was initially genotyped for known published $F 9$ variants by two commercial canine DNA panel testing laboratories and was found to be wildtype. This is not surprising as those published and tested for $F 9$ variants are breed specific and/or even isolated to a single case or family (Table 3). Thus, these non-breed specific results can be misleading breeders, pet owners, and attending veterinary clinicians. Indeed, when genotyping the dam and other family members for the newly identified insertion in the index case, the dam as well as the tested sister were found to be carriers. The identified carrier females and their common dam and granddam were spayed or deceased, respectively, and are no longer a threat to spreading this pathogenic variant. Although there are other untested related dogs in this family, it seems unlikely that this pathogenic F9 variant is widespread. Nevertheless, it was advised that any related Newfoundland dog to this family with bleeding or intended for breeding should be genotyped. Any male with the pathogenic F9 insertion variant should be carefully managed due to increased risk for bleeding or likely humanely euthanized because of poor prognosis, whereas any female testing heterozygous for the specific $F 9$ variant does not exhibit an increased bleeding tendency, but should be spayed (no excessive bleeding expected when heterozygous) and excluded from breeding (half of males affected). 


\section{Conclusions}

Factor IX deficiency, known as hemophilia B, is an X-linked recessive hereditary coagulopathy with severe bleeding tendency and has been reported in various species including multiple canine breeds, but not previously in Newfoundland dogs. It should be noted that DNA variants are typically breed specific and can be caused by de novo mutations in any dog and family. The extent of the spread of the pathogenic variant in the Newfoundland breed is currently unknown, but the F9 insertion seems to be limited to this family.

Supplementary Materials: The following are available online at https:/ /www.mdpi.com/article/10 $.3390 /$ genes12101491/s1, Table S1: Primer sequences used for DNA amplification and sequencing of canine $F 9$ exons and adjacent regions and primer sequences used for TaqMan®SNP Genotyping Assay for $\mathrm{F} 9$ insertion, Figure S1: Amino acid sequence alignments of index case, reference canine, human, and feline FIX protein regions.

Author Contributions: Management of index case and case report, L.S.-V. and J.M.R.; molecular genetic studies, H.K. and A.K.; conceptualization of study, sample recruitment and obtainment of phenotypic results, U.G.; data analysis, H.K., A.K., and U.G.; writing - original draft preparation, H.K., L.S.-V., and U.G.; writing-review and editing, A.K., J.M.R., and E.M.; support and work environment for the molecular genetic studies, A.K. and E.M. All authors have read and agreed to the published version of the manuscript.

Funding: Laboklin GmbH \& Co. KG, Bad Kissingen, Germany provided the workspace and materials and equipment for genomic analyses.

Institutional Review Board Statement: Not applicable.

Informed Consent Statement: Not applicable.

Data Availability Statement: Not applicable.

Acknowledgments: The support and participation of members of the Advanced Veterinary Care Center are greatly appreciated. Laboklin GmbH \& Co. KG kindly provided the work-space, material, and assistance with their technical expertise. We thank the Labogen team in Bad Kissingen, Germany for assistance. The hemostatic testing service offered by Marjory Brooks and the Comparative Coagulation Laboratory, Cornell University, Ithaca, NY, USA are kindly acknowledged.

Conflicts of Interest: H.K., A.K., E.M. are members of Laboklin which offers diagnostic hematological and genetic testing. U.G. was the director of PennGen which offers genetic testing and consultation. He also performed hematologic testing and has been a scientific advisor to Laboklin.

\section{References}

1. Bolton-Maggs, P.H.B.; Pasi, K.J. Haemophilias A and B. Lancet Lond. Engl. 2003, 361, 1801-1809. [CrossRef]

2. Lozier, J.N.; Nichols, T.C. Animal Models of Hemophilia and Related Bleeding Disorders. Semin. Hematol. 2013, 50, 175-184. [CrossRef] [PubMed]

3. Brooks, M. A Review of Canine Inherited Bleeding Disorders: Biochemical and Molecular Strategies for Disease Characterization and Carrier Detection. J. Hered. 1999, 90, 112-118. [CrossRef]

4. Mischke, R. Hämophilie A und B beim Hund. Tierärztl. Prax. Ausg. K Kleintiere Heimtiere 2012, 40, 44-53. [CrossRef] [PubMed]

5. Slappendel, R.J. Congenital (Hereditary) Clotting Disorders in the Dog. Vet. Q. 1998, 20 (Suppl. 1), S41-S43. [CrossRef] [PubMed]

6. Weiss, D.J.; Wardrop, K.J. Schalm's Veterinary Hematology, 6th ed.; Wiley-Blackwell: Hoboken, NJ, USA, 2010; Chapter 86, pp. 661-667. ISBN 978-0-8138-0896-3.

7. Evans, J.P.; Brinkhous, K.M.; Brayer, G.D.; Reisner, H.M.; High, K.A. Canine Hemophilia B Resulting from a Point Mutation with Unusual Consequences. Proc. Natl. Acad. Sci. USA 1989, 86, 10095-10099. [CrossRef] [PubMed]

8. Mauser, A.E.; Whitlark, J.; Whitney, K.M.; Lothorp, C.D.J. A Deletion Mutation Causes Hemophilia B in Lhasa Apso Dogs. Blood 1996, 88, 3451-3455. [CrossRef]

9. Brooks, M.B.; Gu, W. Complete Deletion of Factor IX Gene and Inhibition of Factor IX Activity in a Labrador Retriever with Hemophilia B. J. Am. Vet. Med. Assoc. 1997, 211, 1418-1421.

10. Gu, W.; Brooks, M.; Catalfamo, J.; Ray, J.; Ray, K. Two Distinct Mutations Cause Severe Hemophilia B in Two Unrelated Canine Pedigrees. Thromb. Haemost. 1999, 82, 1270-1275. [CrossRef]

11. Brooks, M.B.; Gu, W.; Barnas, J.L.; Ray, J.; Ray, K. A Line 1 Insertion in the Factor IX Gene Segregates with Mild Hemophilia B in Dogs. Mamm. Genome Off. J. Int. Mamm. Genome Soc. 2003, 14, 788-795. [CrossRef] 
12. Mischke, R.; Kühnlein, P.; Kehl, A.; Langbein-Detsch, I.; Steudle, F.; Schmid, A.; Dandekar, T.; Czwalinna, A.; Müller, E. G244E in the Canine Factor IX Gene Leads to Severe Haemophilia B in Rhodesian Ridgebacks. Vet. J. Lond. Engl. 1997 2011, 187, 113-118. [CrossRef] [PubMed]

13. Brenig, B.; Steingräber, L.; Shan, S.; Xu, F.; Hirschfeld, M.; Andag, R.; Spengeler, M.; Dietschi, E.; Mischke, R.; Leeb, T. Christmas Disease in a Hovawart Family Resembling Human Hemophilia B Leyden Is Caused by a Single Nucleotide Deletion in a Highly Conserved Transcription Factor Binding Site of the F9 Gene Promoter. Haematologica 2019, 104, 2307-2313. [CrossRef]

14. Online Mendelian Inheritance in Animals, OMIA. Sydney School of Veterinary Science. Available online: Https: / Omia.Org/ (accessed on 21 August 2021).

15. O'Leary, N.A.; Wright, M.W.; Brister, R.J.; Ciufo, S.; Haddad, D.; McVeigh, R.; Rajput, B.; Robbertse, B.; Smith-White, B.; Ako-Adjei, D.; et al. Reference Sequence (RefSeq) Database at NCBI: Current Status, Taxonomic Expansion, and Functional Annotation. Nucleic Acids Res. 2016, 44, D733-D745. [CrossRef]

16. SeqSanner; Applied Biosystems/Thermo Fisher Scientific. Available online: https://www.thermofisher.cn/cn/zh/home/ life-science/sequencing/sanger-sequencing/sanger-dna-sequencing/sanger-sequencing-data-analysis.html (accessed on 20 September 2021).

17. Altschul, S.F.; Gish, W.; Miller, W.; Myers, E.W.; Lipman, D.J. Basic Local Alignment Search Tool. J. Mol. Biol. 1990, 215, 403-410. [CrossRef]

18. Jagannathan, V.; Drögemüller, C.; Leeb, T. Dog Biomedical Variant Database Consortium (DBVC) A Comprehensive Biomedical Variant Catalogue Based on Whole Genome Sequences of 582 Dogs and Eight Wolves. Anim. Genet. 2019, 50, 695-704. [CrossRef]

19. Artimo, P.; Jonnalagedda, M.; Arnold, K.; Delphine, B.; Csardi, G.; de Castro, E.; Duvaud, S.; Flegel, V.; Fortier, A.; Gasteiger, E.; et al. ExPASy: SIB Bioinformatics Resource Portal. Nucleic Acids Res. 2012, 40, W597-W603. [CrossRef]

20. Wisdom Panel ${ }^{\mathrm{TM}} \mid$ World's Leading DNA Test Service for Dogs and Cats. Available online: https://www.wisdompanel.com/enus/ (accessed on 23 August 2021).

21. Vetnostic Laboratories ${ }^{\circledR}$. Available online: https://www.vetnostic.com/ (accessed on 23 August 2021).

22. Russell, K.E.; Olsen, E.H.N.; Raymer, R.A.; Merricks, E.P.; Bellinger, D.A.; Read, M.S.; Rup, B.J.; Keith Jr, J.C.; McCarthy, K.P.; Schaub, R.G.; et al. Reduced Bleeding Events with Subcutaneous Administration of Recombinant Human Factor IX in Immune-Tolerant Hemophilia B Dogs. Blood 2003, 102, 4393-4398. [CrossRef] [PubMed]

23. den Dunnen, J.T.; Dalgleish, R.; Maglott, D.R.; Hart, R.K.; Greenblatt, M.S.; McGowan-Jordan, J.; Roux, A.-F.; Smith, T.; Antonarakis, S.E.; Taschner, P.E.M. HGVS Recommendations for the Description of Sequence Variants: 2016 Update. Hum. Mutat. 2016, 37, 564-569. [CrossRef]

24. Schmidt, A.E.; Bajaj, S.P. Structure-Function Relationships in Factor IX and Factor IXa. Trends Cardiovasc. Med. 2003, 13, 39-45. [CrossRef]

25. Hwang, J.; Kim, Y.K. When a Ribosome Encounters a Premature Termination Codon. BMB Rep. 2013, 46, 9-16. [CrossRef] [PubMed]

26. Sievers, F.; Wilm, A.; Dineen, D.; Gibson, T.J.; Karplus, K.; Li, W.; Lopez, R.; McWilliam, H.; Remmert, M.; Söding, J.; et al. Fast, Scalable Generation of High-Quality Protein Multiple Sequence Alignments Using Clustal Omega. Mol. Syst. Biol. 2011, 7, 539. [CrossRef]

27. Wulff, K.; Schröder, W.; Wehnert, M.; Herrmann, F.H. Twenty-Five Novel Mutations of the Factor IX Gene in Haemophilia B. Hum. Mutat. 1995, 6, 346-348. [CrossRef]

28. Rallapalli, P.M.; Kemball-Cook, G.; Tuddenham, E.G.; Gomez, K.; Perkins, S.J. An Interactive Mutation Database for Human Coagulation Factor IX Provides Novel Insights into the Phenotypes and Genetics of Hemophilia B. J. Thromb. Haemost. JTH 2013, 11, 1329-1340. [CrossRef] [PubMed]

29. McVey, J.H.; Rallapalli, P.M.; Kemball-Cook, G.; Hampshire, D.J.; Giansily-Blaizot, M.; Gomez, K.; Perkins, S.J.; Ludlam, C.A. The European Association for Haemophilia and Allied Disorders (EAHAD) Coagulation Factor Variant Databases: Important Resources for Haemostasis Clinicians and Researchers. Haemophilia 2020, 26, 306-313. [CrossRef]

30. Nazeef, M.; Sheehan, J.P. New Developments in the Management of Moderate-to-Severe Hemophilia B. J. Blood Med. 2016, 7, 27-38. [CrossRef] [PubMed]

31. Nichols, T.C.; Hough, C.; Agerso, H.; Ezban, M.; Lillicrap, D. Canine Models of Inherited Bleeding Disorders in the Development of Coagulation Assays, Novel Protein Replacement and Gene Therapies. J. Thromb. Haemost. 2016, 14, 894-905. [CrossRef] [PubMed]

32. Franchini, M.; Mannucci, P.M. The History of Hemophilia. Semin. Thromb. Hemost. 2014, 40, 571-576. [CrossRef] 